\title{
The Innovation Lessons from Double-Fluid Electrospinning Processes for College Students
}

\author{
Yaoyao Yang, Haohan Chen, Zhubei cheng, Yongchang Xu, Yangluo Qu, Deng-Guang Yu* \\ School of Materials Science and Engineering University of Shanghai for Science and Technology \\ 516 Jungong Road, Shanghai 200093, China \\ ydg017@usst.edu.cn \\ *Corresponding author
}

\begin{abstract}
In science and engineering field of higher education, it is very important for undergraduate students to grasp some types of the modern advanced technologies. However, the even more important is that the students should have a comprehensive understanding about the meaning of innovation in the advanced technologies. With double-fluid electrospinning being a model of modern advanced nanotechnologies, the paper refines a series of teaching materials from the perspective of working processes, the final products and nanostructures, the applications of electrospun nanoproducts and their formation mechanisms. These materials are outcomes of brilliant "scientific researches feeding back high educations" and are very useful for cultivating the students' learning and practice interests on the advanced technologies, and fostering their capability of innovations and resolving complicated engineering problems.
\end{abstract}

Keywords-Innovation Lesson; College students; Double-fluid electrospinning; Advanced technology; Complex engineering problem

\section{INTRODUCTION}

In today modern society, a series of advanced technologies occurred in an accelerating speed in a wide variety of fields. Particularly, new nanotechnologies for creating nanomaterials are reported everyday in literature. This rapid development, on one hand, requires the college students majoring in science and engineering have a fine grasp of them. And on the other hand, the teachers should draw out the common meanings from the advanced technologies for training the students, to foster their innovation capability, and make their engineering lessons vivid and impressive to the students.

Often, with the advanced technology as a core, a series of complicated engineering problems can be drawn out. During the processes of resolving these problems, the students and even their teachers can be taught to carry out innovative scientific activities. Shown in Fig. 1 is a schematic about electrospun nanoribbons utilized to treat $\mathrm{Pb}$ polluted water [1]. The key element is the double-fluid electrospinning process, i.e. the modified coaxial electrospinning. Several complicated engineering problems can be concluded as follows: 1) the systematic selections of crude materials and their matching extents; 2) the implementation of a modified coaxial electrospinning under an optimized condition (which often means that a series of operational parameters are matched with each other); and 3) the application effects in removing the $\mathrm{Pb}$ ion from the waste water.

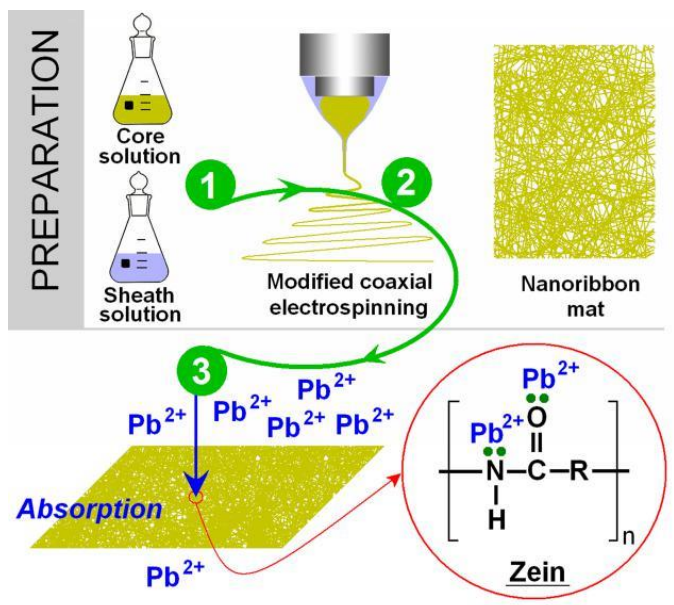

APPLICATIONS--WATER TREATMENT

Fig. 1 Advanced technology can act as a key element for a series of complicated engineering problems and can be fully exploited as innovation teaching materials for the college students [1]

During the resolution processes, a series of materials can be refined out for utilization as innovation teaching materials. A picture showing the step-by-step processes and their training lessons are included in Fig. 2. The first step is the reasonable selection of polymer matrix, which should have fine filamentforming property [2-9]. Meanwhile, the exploitation of solvent that is utilized for preparing the working solution is an important issue, which should ensure good electrospinnability of working fluid [10-16]. The second step is the electrospinning process and the creation of electrospun nanofibers, during which a series of parameters and also the working format can be innovatively changed for forming high quality nanoproducts [17-21]. The third step is the potential applications of the prepared nanofibers, which may or may not reach the initial design goal. During this step, the structureperformance relationship is one of the most important issue that can be explored to instruct the similar job in future. All the above-mentioned steps are mainly on the level of engineering. Beyond this should be the forth step, i.e. the related mechanisms and theories, both about the material formation and also about the functional applications. 


\begin{tabular}{|c|l|l|}
\hline Order & Progress & Innovation lessons \\
\hline $\mathbf{1}$ & $\begin{array}{l}\text { Starting } \\
\text { polymer }\end{array}$ & Material matching \\
\cline { 1 - 3 } & $\begin{array}{l}\text { Electrospun } \\
\text { nanofibers }\end{array}$ & New working processes \\
\cline { 3 - 4 } & $\begin{array}{l}\text { Functional } \\
\text { applications }\end{array}$ & $\begin{array}{l}\text { New structure-performance } \\
\text { relationship }\end{array}$ \\
\hline $\mathbf{4}$ & $\begin{array}{l}\text { Mechanisms } \\
\text { \& Theories }\end{array}$ & $\begin{array}{l}\text { EHDA theories } \\
\text { Functional mechanism }\end{array}$ \\
\hline
\end{tabular}

Fig. 2 Implementation of a double-fluid electrospinning process and the potential innovation lessons that can be drawn out from the forward processes.

\section{InNOvation LeSSONS From Double-Fluid ELECTROSPINNING WORKING PROCESSES}

It is easy to take for granted that one-fluid electrospinning forwarded to the two-fluid coaxial electrospinning is an easy thing, which should not contain any innovation meanings. But the facts are just opposite. Although a simple increase of working fluid from one fluid to double fluids, the implementation difficulty increase tremendously. Meanwhile, the usefulness of the generated nanoproducts would greatly expand. Thus, it is not strange that Prof. Dennis once declared that the occurrence of coaxial electrospinning is one of the most important things in the field of electrohydrodynamic atomization [22].

In this example that is specially selected for explaining innovations to the college students, the coaxial electrospinning is a modified one [10-12]. In this new process, the sheath working fluid is not an electrospinnable solution but a pure organic solvent mixture. This innovation looks very simple, but it has broken a traditional concept about the traditional coaxial electrospinning that the sheath working fluid must be electrospinnable for carrying out a successful double-fluid working process. Certainly, this innovation means a lot of innovative results, not only the process itself, but also the generated nanoproducts.

Shown in Fig. 3 is a comparison of the single-fluid electrospinning of zein solution (A) and the modified coaxial electrospinning with a blank solvent as the sheath working fluid (B). Because the strong interactions between the zein molecules and the metal nozzle of spinneret, the single-fluid electrospinning process is gradually stopped by the semi-solid substances formed around the nozzle. Manual removements of these substances for ensuring a continuous preparation process are required, which is time-consuming and tedious. In sharp contrast, the modified coaxial electrospinning can always keep a robust and continuous generation process without any personal intervention. These interesting phenomena greatly provoke the students' interests on the innovations about this advanced technology. We believe that more and more new coaxial processes can be imagined out by them in future.

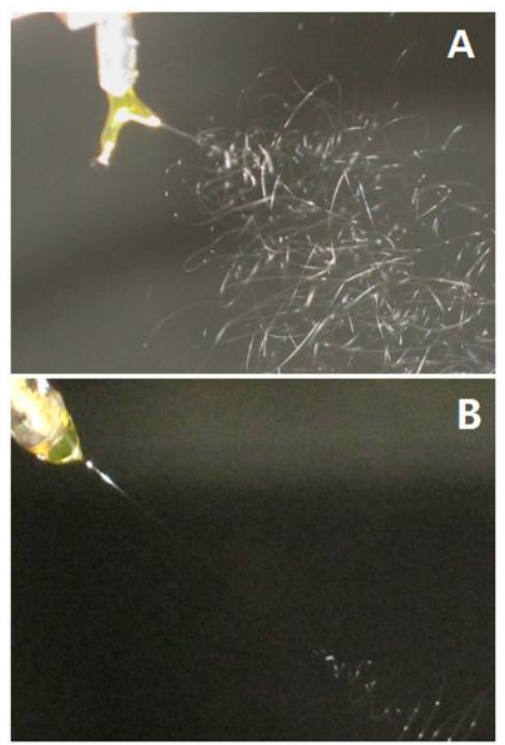

Fig. 3 The innovation lessons from the single-fluid electrospinning of pure zein solution (A) to the modified coaxial electrospinning (B) with a solvent mixture as a sheath fluid to smooth and stabilize the working processes [1].

\section{INNOVATION LeSSONS From DOUBLE-FLuID ELECTROSPUN NANOSTRUCTURES}

In a common sense, people always think that the electrospun nanofibers should take a morphology of round and smooth. However, some electrospun nanofibers are flat. And what is more the round and flat nanofibers can be manipulated through the experimental conditions. This also comprise an interesting innovation lesson to the college students about electrospun nanoproducts.
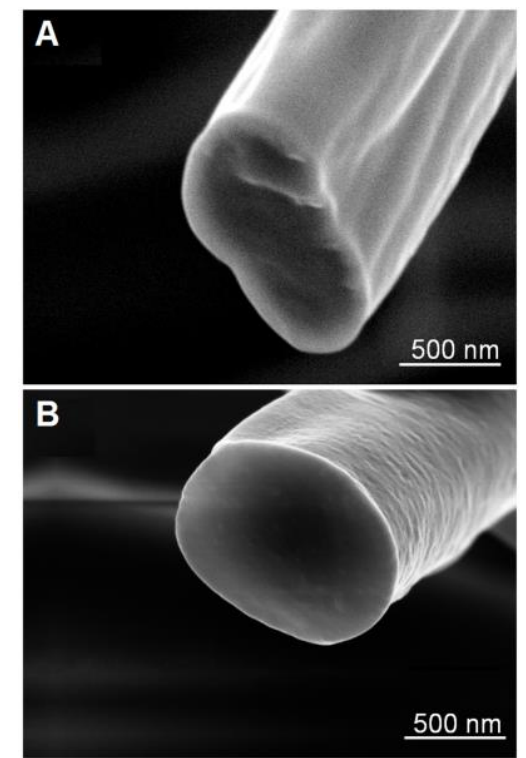

Fig. 4 The innovation lesson about different kind of nanoproducts: A-flat nanofibers; B-round nanofibers [23]. 
Shown in Fig. 4 are all nanoproducts prepared from the zein solutions but from different electrospinning processes. The nanofiber in Fig. 4A has a flatter morphology was prepared using the traditional single-fluid electrospinning process. The nanofiber in Fig. 4B has a rounder morphology was prepared using the double-fluid modified coaxial electrospinning process. Thus, the innovation contents explained to the students include not only a new modified coaxial process, but also the nanoproducts with different and unanticipated morphology.

\section{InNOVATION LESSONS From the APPLICATIONS AND Formation MECHANISMS OF DOUbLE-FLuID ElECTROSPUN NANOPRODUCTS}

In the zein molecule, there are many $-\mathrm{NH}$ and $-\mathrm{C}=\mathrm{O}$ groups, which can attract $\mathrm{Pb}$ ions through electrostatic interactions, which is shown as Fig. 5A. When the abovementioned nanofibers are exploited to treat $\mathrm{Pb}$ polluted water, the flat zein nanofibers can provide a better treatment effects than the round zein nanofibers. This can be explained by the fact that the round nanofibers has a totally smaller surface area than the flat nanofibers.
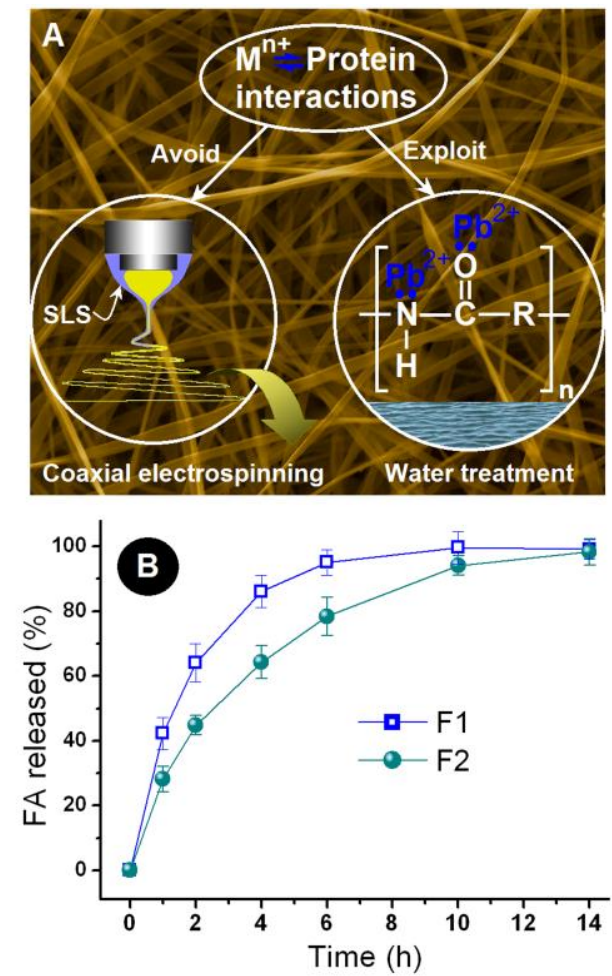

Fig. 5 The innovation lessons about the application of electrospun nanoproducts: A-mechanism of zein absorbing $\mathrm{Pb}$ ions from waste water [1]; B-Functional performances of two medicated nanofibers: F1-flat nanofibers; F2-round nanofibers [23]

However, when the zein nanofibers are exploited to manipulate drug controlled release profiles, the flat nanofibers (F1 in Fig. 5B) shows a poorer drug sustained release profiles than the round zein nanofibers. This entirely different effects can impress the students deeply that even the shape of nanoproduct can play their important roles in determining the materials' functional performances. Certainly, these contents comprise useful teaching materials for guiding the college students to think about their own innovations.

Based on the differences between the single-fluid electrospinning and double-fluid coaxial electrospinning, the theoretical lessons about the nanofiber formation mechanisms can also be explained clearly to the students. On one hand, just as the traditional blending electrospinning, the modified coaxial electrospinning has the typical three successive steps, which is shown in Fig. 6A. The Taylor cone, the straight fluid jet, the bending and whipping loops, and the different kinds of electrical forces exerting on the working fluids during the coaxial processes are all apparently similar with those happening in the one-fluid process. But the details are different because of two working fluids are involved. Shown in Fig. 6B, the initiation of coaxial electrospinning is a balance between the electrical field $(E)$ and the surface tension of sheath working fluid $\left(\gamma_{0}\right)$, but the core-sheath fluids interfacial surface tension $\left(\gamma_{\text {inter }}\right)$ should exert its influences on the electrospinning processes and also the quality of the resultant nanofibers. Similar with the double-fluid coaxial electrospinning, a wide variety publications about double-fluid coaxial electrospraying can be similarly explored as teaching materials for carrying out innovation lessons to the college students in high school [24-29].

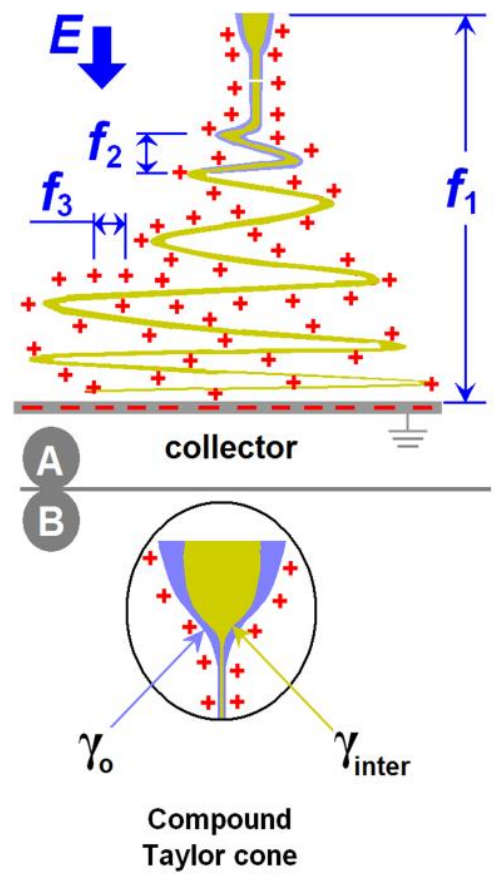

Fig. 6 The innovation lesson about the fiber formation mechanisms from the double-fluid electrospinning processes: A-the three steps of a modified coaxial electrospinning process; B-the formation of a compound Taylor cone [1]. 


\section{SUMMARY}

With a brand-new nanotechnology--modified coaxial electrospinning as an excellent example, the present paper has refined a series of interesting topics that can be utilized as teaching materials for innovation education in high school. The working processes of modified coaxial electrospinning, the formation of nanoproduct with different kinds of shapes and structures, and their influences on the functional performances are analyzed in details to disclose the buried innovation teaching meanings. Besides, the related theoretical lessons about the nanofiber formation mechanisms from the double-fluid process are also discussed. This job opens a new platform for innovation education in high school, on which the advanced technologies can be exploited as source materials, scientific researches can feed back education, and the teachers can share their experiences with the college students.

\section{ACKNOWLEDGMENT}

The financial supports from the following projects are appreciated: the Shanghai Education Science Research Project (C17058), the 2017 Graduate curriculum reform project in USST, the National/Shanghai/USST College Student Innovation Project (Nos. grant number: XJ10252324-330, SH10252194 and N201810252044-46-47)

\section{REFERENCES}

[1] H.F. Wen, C. Yang, D.G. Yu, X.Y. Li, D.F. Zhang, "Electrospun zein nanoribbons for treatment of lead-contained wastewater," Chem. Eng. J., vol.290, pp.263-272, 2016.

[2] D.G. Yu, C. Yang, M. Jin, G.R. Williams, H. Zou, X. Wang, et al, "Medicated Janus fibers fabricated using a Teflon-coated side-by-side spinneret," Colloid. Surface B, vol.138, pp.110-116, Feburary 2016.

[3] Q. Wang, H.P. Li, C. Yang, J.J. Li, and D.G. Yu, "Beads-on-a-string amorphous solid dispersion fabricated using a modified coaxial electrospinning," J. Control. Release, vol.259, pp.e111-e112, 2017.

[4] Y.H. Wu, D.G. Yu, H.P. Li, X.Y. Wu, and X.Y. Li, "Medicated structural PVP/PEG composites fabricated using coaxial electrospinning," e-Polymers, vol.17, pp.39-44, January 2017.

[5] D.G. Yu, H.P. Li, C. Yang, J.J. Li, Q. Wang, and G.R. Williams, "Double-pulsatile release core-shell fibers fabricated using modified tri-axial electrospinning,” J. Control. Release, vol.259, pp.e24-e25, 2017.

[6] J.J. Li, Chen Yang, Hai-Peng Li, Qing Wang, and Deng-Guang Yu, "Oral controlled release in accordance with drug adsorption biological rhythm provided by an electrospun structural amorphous solid dispersion," J. Control. Release, vol.259, pp.e61-e62, 2017.

[7] X. Liu, W. Shao, M. Luo, J. Bian, D.G. Yu, "Electrospun blank nanocoating for improved sustained release profiles from medicated gliadin nanofibers," Nanomaterials, vol.8, Article ID 184 (11 pages), 2018.

[8] C. Yang, D.G. Yu, D. Pan, X.K. Liu, X. Wang, S.W.A. Bligh, et al, "Electrospun pH-sensitive core-shell polymer nanocomposites fabricated using a tri-axial processes," Acta Biomater., vol.35, pp.77-86, April 2016.

[9] G.Z. Yang, H.P. Li, J.H. Yang, J. Wan, and D.G. Yu, "Influence of working temperature on the formation of electrospun polymer nanofibers," Nanoscale Res. Lett., vol.12, Article 15, January 2017.

[10] Y.Y. Yang, Z.P. Liu, D.G. Yu, K. Wang, P. Liu, X. Chen, "Colonspecific pulsatile drug release provided by electrospun shellac nanocoating on hydrophilic amorphous composites," Int. J. Nanomed., vol.2018, pp. 2395-2404, 2018.

[11] Q. Wang, D.G. Yu, L.L. Zhang, X.K. Liu, Y.C. Deng, and M. Zhao,
"Electrospun hypromellose-based hydrophilic composites for rapid dissolution of poorly water-soluble drug," Carbohydr. Polym., vol.174, pp.617-625, Oct, 2017.

[12] Y.H. WU, C. Yang, X.Y. Li, J.Y. Zhu, and D.G. Yu, "Medicated nanofibers fabricated using $\mathrm{NaCl}$ solutions as shell fluids in a modified coaxial electrospinning," J. Nanomater., vol.2016, Article ID 8970213, 2016.

[13] K. Wang, X.K. Liu, X.H. Chen, D.G. Yu, Y.Y. Yang, and P. Liu, "Electrospun hydrophilic Janus nanocomposites for the rapid onset of therapeutic action of helicid," ACS Appl. Mater. Interfaces, vol.10, pp.2859-2867, 2018.

[14] G.Z. Yang, J.J. Li, D.G. Yu, M.F. He, J.H. Yang, and G.R. Williams, "Nanosized sustained-release drug depots fabricated using modified triaxial electrospinning," Acta Biomater., vol.53, pp.233-241, April 2017.

[15] Y. Xu, J.J. Li, D.G. Yu, G.R. Williams, J.H. Yang, and X. Wang, "Influence of the drug distribution in electrospun gliadin fibers on drugrelease behavior," Eur. J. Pharm. Sci., vol.106, pp.422-430, August 2017.

[16] Z. Zhang, W. Li, G. Wang, Y.L. Qu, and D.G. Yu, "Electrospun 4th generation solid dispersions of poorly water-soluble drug utilizing two different processes," J. Nanomater. Vol.2018, Article ID 2012140, 2018.

[17] Q. Wang, D.G. Yu, S.Y. Zhou, C. Li, and M. Zhao, "Fabrication of amorphous electrospun medicated-nanocomposites using a Teflonbased concentric spinneret," e-Polymer, vol.18, pp.3-11, 2018.

[18] D.G. Yu, J.J. Li, M. Zhang, and G.R. Williams, "High-quality Janus nanofibers prepared using three-fluid electrospinning," Chem. Commun., vol.53, pp.4542-4545, April 2017.

[19] Y.H. Wu, D.G. Yu, J.J. Li, Q. Wang, H.P. Li, and X.Y. Li, "Medicated multiple-component polymeric nanocomposites fabricated using electrospraying," Polym. Polym. Compos., vol.25, pp.57-62, 2017.

[20] M. Jin, D.G. Yu, X. Wang, C.F.G.C. Geraldes, G.R. Williams, and S.W.A. Bligh, "Electrospun contrast agent-loaded fibers for colontargeted MRI,” Adv. Healthcare Mater., vol.5, pp.977-985, April 2016.

[21] Y.H. WU, H.P. Li, X.X. Shi, J. Wan, Y.F. Liu, and D.G. Yu, "Effective utilization of the electrostatic repulsion for improved alignment of electrospun nanofibers," J. Nanomater., vol.2016, Article ID2067383, 2016.

[22] Y. Dzenis, "Spinning continuous fibers for nanotechnology," Science vol. 304, pp.1917-1919, 2004.

[23] J.M. Yang, L. Zha, D.G. Yu, J. Liu, "Coaxial electrospinning with acetic acid for preparing ferulic acid/zein composite fibers with improved drug release profiles," Colloid. Surface B, vol.102, pp.737743, 2012.

[24] X.Y. Li, Z.B. Zheng, D.G. Yu, X.K. Liu, Y.L. Qu, and H.L. Li, "Electrosprayed sperical ethylcellulose nanoparticles for an improved sustained-release profile of anticancer drug," Cellulose, vol.24, pp.5551-5564, 2017.

[25] Z.P. Liu, Y.Y. Zhang, D.G. Yu, D. Wu, and H.L. Li, "Fabrication of sustained-release zein nanoparticles via modified coaxial electrospraying,” Chem. Eng. J., vol.334, pp.807-816, 2018.

[26] Y.Y. Yang, M. Zhang, Z.P. Liu, K. Wang, and D.G. Yu, "Meletin sustained-release gliadin nanoparticles prepared via solvent surface modification on blending electrospraying," App. Surf. Sci., vol.434, pp.1040-1047, 2018.

[27] K. Wang, H.F. Wen, D.G. Yu, Y. Yang, and D.F. Zhang, "Electrosprayed hydrophilic nanocomposites coated with shellac for colon-specific delayed drug delivery," Mater. Design, vol.143, pp.248$255,2018$.

[28] Z.P. Liu, L.L. Zhang, Y.Y. Yang, D. Wu,G. Jiang, and D.G. Yu, "Preparing composite nanoparticles for immediate drug release by modifying electrohydrodynamic interfaces during electrospraying," Powder Technol., vol.327, pp.179-187, 2018.

[29] Y.Y. Yang, M. Zhang, K. Wang, and D.G. Yu. "pH-sensitive polymer nanocoating on hydrophilic composites fabricated using modified coaxial electrospraying," Mater. Lett., vol.227, pp. 93-96, 2018. 